\title{
The Museum Speaks - Your Narrative or Mine? The Museum in a Web 2.0 World
}

\author{
Susan Hazan \\ The Israel Museum \\ Jerusalem \\ Israel \\ www.musesphere.com/about/Susan.Hazan.html \\ shazan@imj.org.il
}

\begin{abstract}
When we encounter material objects in the gallery - artworks or archaeological artefacts - we are reading narratives authored in the institutional voice of the museum that can be compelling but, at the same time, through their opaque structure, can be totalizing in their delivery. In reading these macronarratives we are assured that this is the story whether it is national, local or historical in nature. How could these persuasive narratives be seen as less than irrevocable, especially when they are punctuated by the physical evidence that is laid out in front of our very own eyes? However, when 'normative' displays of 'our' heritage, or 'our' shared memory are presented in the gallery not all visitors will necessarily concur with this message. Visitors may, of course, comply with the story line and will readily engage with the narrative; alternatively, the exhibition message may be read in opposition, while at other times visitors may simply react indifferently.
\end{abstract}

However, when the exhibition is located online these very same narratives represent but a single resource amongst many, and in a knowledge society, these narratives may now be read as one of the myriad of stories, that eventually tumble into the palm of our hand. In reality, we obviously collate our preferred knowledge from more than one source, and move from place to place, collecting units of fragmented stories as a bricoleur not only from museums, but a wealth of print sources and the electronic media; diligently gathering information where ever we find it.

At the same time, we are authoring our own micronarratives and distributing them back in the maelstrom together with millions of other micronarratives over social media - Facebook, Twitter, YouTube and a host of other popular platforms. All these narratives fold into one another; creating the fabric of our own cultural heritage landscape - or unwrap themselves along our own pathways; opening up new opportunities for self-directed learning and highly subjective, yet increasingly creative ways of thinking about self; past and present.

This presentation locates the Museum in the fulcrum of this information flux to discuss the different ways these stories are spun to ask the question "when the Museum speaks - is this your narrative or mine?" 